\title{
Oficinas de promoção de saúde: discutindo os dilemas do cotidiano de um grupo de agentes comunitárias de saúde
}

\author{
Jacqueline Isaac Machado Brigagão $^{1}$ \\ Roselane Gonçalves \\ Universidade de São Paulo, São Paulo-SP, Brasil
}

\begin{abstract}
Resumo: Este artigo apresenta um relato de experiência sobre o desenvolvimento de oficinas de promoção de saúde com um grupo de agentes comunitárias de saúde na zona leste de São Paulo. Inicia-se contextualizando o grupo, a profissão de agente comunitário de saúde e as políticas públicas. A seguir, apresenta-se a descrição e a discussão das oficinas realizadas com esses profissionais, cujo objetivo era possibilitar um espaço de diálogo sobre as práticas do cotidiano de trabalho. Ao final das oficinas, as agentes comunitárias de saúde relataram novos modos de pensar e lidar com os desafios do trabalho na comunidade.
\end{abstract}

Palavras-chave: grupos, gênero, promoção da saúde.

\section{Workshops for health promotion: discussing the dilemmas of the daily routine of a group of community health agents}

\begin{abstract}
This article presents an experience report on the development of workshops for health promotion with a group of community health agents in the East of the city of São Paulo, SP, Brazil. It first contextualizes the group, the community health agent profession and related public policies. Afterwards, it describes and discusses the workshops offered to these professionals, whose main goal was to promote a dialogue about their daily practices. At the end of the workshops, the community health agents reported new ways of thinking and dealing with challenges posed in their daily work in the community.
\end{abstract}

Keywords: groups, gender, health promotion.

\section{Talleres de promoción de salud: los dilemas cotidianos de un grupo de agentes comunitarios de salud}

\begin{abstract}
Resumen: Este artículo presenta un relato de experiencias en los talleres de promoción de salud, con un grupo de agentes comunitarios de salud de la zona este de São Paulo. El texto presenta una breve explicación del contexto social del grupo, de la profesión del agente comunitario de salud, de la política pública así como la descripción y discusión de los talleres realizados. El objetivo de los talleres es permitir un espacio para el diálogo sobre las prácticas del trabajo diario. Al final de los talleres, los agentes comunitarios de salud relataron nuevas formas de pensar y hacer frente a los desafíos del trabajo cotidiano en la comunidad.
\end{abstract}

Palabra clave: grupos, género, promoción de la salud.

O papel dos Agentes Comunitários de Saúde (ACS) passa a fazer parte das políticas públicas federais com a criação do Programa Nacional de Agentes Comunitários de Saúde criado pelo Ministério da Saúde em 1991. Em 1997, a portaria $\mathrm{n}^{\circ} 1.886$ aprova as diretrizes do Programa de Agentes Comunitários e do Programa de Saúde da Família (PSF) e define que as atribuições dos ACS são a promoção de saúde e ações de prevenção estabelecidas de acordo com as necessidades de saúde do território no qual os agentes atuam.

Desde os anos 1980, com o movimento da Reforma Sanitária e a criação do Sistema Único de Saúde (SUS), houve mudanças significativas no modelo de assistência à saúde. $\mathrm{O}$ município passa a assumir gradativamente o protagonismo nas ações de saúde (Brigagão \& Oliveira, 2005) e as políticas

\footnotetext{
1 Endereço para correspondência:

Profa. Dra Jacqueline Isaac Machado Brigagão. Universidade de São Paulo. Escola de Artes, Ciências e Humanidades. Curso de Obstetrícia. Rua Arlindo Béttio, 1000. CEP 03.828-000. São Paulo-SP, Brasil. E-mail: jac@usp.br
}

de saúde implementadas realizam um verdadeiro deslocamento da assistência de um modelo médico-curativo, com o foco nos indivíduos, para um modelo voltado à atenção integral, onde a promoção de saúde ocupa um papel central. Essas políticas são orientadas pela noção de que a saúde da população está intimamente associada às condições de vida da comunidade a que ela pertence.

O PSF é um exemplo claro dessa reorientação do modelo de atenção à saúde. A idéia central desse programa é que as famílias de um mesmo bairro serão atendidas por uma equipe de saúde composta basicamente por um médico, um enfermeiro, um auxiliar de enfermagem e quatro a seis agentes comunitários de saúde (ACS). Há a possibilidade de incorporar outros profissionais às equipes ou formar equipes de apoio, de acordo com as necessidades e os recursos locais. A equipe é responsável pela realização de visitas domiciliares regulares, por meio das quais cria vínculos que possibilitam desenvolver ações que promovam o desenvolvimento integrado do ser humano e da comunidade. Desse modo, há uma relação mais próxima na qual a família identifica sua equipe de referência, que se responsabiliza por sua promoção de 
saúde e, como conhecem bem suas necessidades, são capazes de realizar Projetos Terapêuticos Singulares para atender a demandas individuais específicas (Campos, 2005).

O PSF traz a proposta de que a equipe de referência seja o canal direto das famílias com o sistema de saúde e, quando são necessárias intervenções mais complexas, é a equipe de referência quem faz os encaminhamentos e os agendamentos do atendimento. Assim cada equipe é responsável por um número de pessoas pertencentes às famílias de uma determinada região dentro do bairro. Os ACS tornam-se mediadores entre a comunidade e os serviços de saúde, valorizando e incorporando os saberes populares na construção de um modelo de cuidado menos medicalizado e mais inclusivo (Bornstein \& Stotz, 2008).

A discussão proposta por este artigo dá continuidade ao diálogo promovido por estudos anteriores que apontaram limitações na formação dos ACS no que se refere a saberes sistematizados que priorizem os aspectos mais políticos e sociais e que utilizem metodologias problematizadoras (Kluthcovsky \& Takayanagui, 2006; Bornstein \& Stotz, 2008).

O objetivo deste artigo é refletir sobre a potencialidade das metodologias participativas para a discussão e problematização das dificuldades e conflitos vivenciados no cotidiano do trabalho por agentes comunitárias de saúde vinculadas ao Programa de Saúde da Família e para a formação continuada destes profissionais. No relato desta experiência será apresentada uma breve discussão sobre a inserção dos ACS nas políticas públicas de saúde, o contexto em que o trabalho foi desenvolvido, a análise e discussão dos principais temas problematizados nas oficinas.

\section{Método}

\section{$O$ contexto da intervenção}

A zona leste da cidade de São Paulo é considerada a mais populosa deste município. Nessa região vive $1 / 3$ da população de São Paulo, cerca de quatro milhões de habitantes, distribuídos numa área equivalente a $22 \%$ do território do município. Apesar de representar parcela expressiva dos trabalhadores da cidade, grande parte da população da região sofre com o desemprego e suas famílias vivem em situação de carência. O Índice de Desenvolvimento Humano (IDH) da região leste é de 0,478 , bem abaixo da média mínima que seria de 0,84 . É essencialmente formada por estabelecimentos de comércio e moradia popular, sendo considerada uma região dormitório da cidade. A renda média da população está abaixo da média da cidade e a taxa de criminalidade é elevada, há carência de equipamentos de saúde e de educação (Câmara Municipal de São Paulo, 2007).

Nesse contexto, a zona leste de São Paulo caracteriza-se por ser uma região com muitas necessidades de saúde e educação, e a criação de uma Escola da Universidade São Paulo (USP) criou expectativas de diversas ordens na comunidade circunvizinha e uma demanda de ações concretas que possam contribuir para a transformação da realidade local. Assim, a questão da formação dos ACS foi apresentada às docentes pelas lideranças locais como uma prioridade das ações de saúde na região. Em conversa com a gerente da Unidade de Saúde da Família mais próxima ao campus da USP tomou-se conhecimento das dificuldades do PSF local e das expectativas quanto à realização de atividades junto às agentes que incluíssem as temáticas: violência, saúde e o trabalho com adolescentes. Para tanto, seria necessário obter a autorização da Coordenadoria Regional de Saúde Leste, que foi lavrada em março e em abril de 2007 iniciou-se o trabalho.

O diálogo inicial com as lideranças foi motivado pela perspectiva das autoras de que a proximidade, o diálogo e as ações conjuntas com a comunidade possam contribuir na construção de novos conhecimentos e na transformação da realidade. Essa aproximação permitiu conhecer a realidade local e, a partir daí, criar projetos de extensão universitária em consonância com as necessidades da população.

\section{Participantes}

A Unidade de Saúde da Família (USF) a que pertencem as agentes é composta por duas equipes do PSF. O bairro possui em média 7.500 habitantes e 1.978 famílias. Cada equipe era composta por cinco agentes comunitários de saúde, um enfermeiro, um médico e um agente administrativo. Havia oito agentes nas duas equipes de saúde, sendo que em média seis participavam a cada encontro. Salienta-se que as equipes de agentes não estavam completas, aguardava-se a contratação de uma agente de saúde e outra estava em licença médica. Em geral, cada ACS assumia o acompanhamento de 200 famílias em média. As agentes de saúde desempenhavam um papel central neste modelo já que eram responsáveis pelas visitas domiciliares periódicas e faziam a interlocução entre a comunidade e a equipe de saúde.

\section{Procedimentos}

A seguir descreveremos os aspectos teóricos e técnicos que nortearam a realização das oficinas. $\mathrm{O}$ trabalho foi orientado por uma perspectiva crítica e política de Psicologia Social que busca refletir sobre os desafios e dilemas do presente e articulá-los com as construções históricas que o atravessam transversalmente e estão sempre a mediar suas possibilidades.

A metodologia utilizada nas oficinas foi orientada por uma perspectiva construcionista social, que entende o conhecimento como sendo elaborado em conjunto pelas pessoas, ou seja, sendo sempre resultado de uma ação coletiva (Iñiguez, 2004). Assim, buscou-se possibilitar espaços para que as pessoas pudessem construir novos conhecimentos por meio do diálogo e das trocas conversacionais e da produção de novos sentidos (Spink, 2004).

As estratégias utilizadas nas atividades buscavam problematizar as questões discutidas e a participação ativa de todos os envolvidos (Freire, 1996). As oficinas foram organizadas como espaços de troca e de conversação que possibilitavam a reflexão crítica das práticas discursivas do cotidiano 
de trabalho das agentes de saúde, a construção de novos sentidos e fazeres e enfatizavam a dimensão local, “já que o ser humano é um ser em situação e pensar a sua situcionalidade é fundamental para a sua compreensão como um ser de práxis" (Oliveira \& Carvalho, 2007, p.221).

No período de abril a dezembro de 2007 foram realizadas 16 oficinas com a duração de 2 horas cada. Em consonância com a perspectiva proposta, as oficinas foram organizadas como espaços democráticos de troca onde se buscava sempre compartilhar saberes de modo cooperativo e permitir a circulação do poder/saber entre as participantes. O tema central dos encontros foi definido coletivamente e incluíram: (a) as relações de gênero; (b) as diversas formas de violência; (c) os direitos sexuais e reprodutivos. Porém, havia sempre espaço para a discussão de questões emergentes, que permitia uma horizontalidade nas interações e nas discussões dos temas de modo a diminuir a desigualdade na relação de saberes entre as facilitadoras e as agentes. Os temas eram apresentados por uma ou mais agentes e a discussão era norteada pelos saberes e questões trazidas por elas. As facilitadoras propunham atividades e estratégias metodológicas que buscavam fomentar a reflexão crítica sobre estas questões e a produção coletiva de novos sentidos.

As oficinas eram centradas no diálogo e em geral organizadas em três momentos: chegada, discussão/realização de atividades e fechamento. No momento inicial eram realizadas dinâmicas de grupo, jogos e exercícios. Algumas vezes foram utilizados filmes que buscavam facilitar a integração do grupo e funcionavam como disparadores do diálogo. Em seguida, o grupo elegia o tema que seria trabalhado no dia e iniciava-se a discussão que, muitas vezes, era concretizada através da construção de cartazes, colagens, desenhos, entre outros. Ao final das oficinas buscava-se fechar as atividades com o relato de todas as participantes sobre o que lhes pareceu importante nas discussões e sobre as novas questões que haviam surgido. As facilitadoras das oficinas assumiam a postura de problematizadoras e mediadoras dos diálogos, apontavam para as participantes as contradições e conflitos presentes nas conversas e a importância de ouvir e respeitar o outro.

Quanto aos cuidados éticos, cabe salientar que o trabalho foi autorizado pela Coordenadoria Regional de Saúde Leste e as participantes assinaram o Termo de Consentimento Livre e Esclarecido, como previsto na portaria 196/96 do Ministério da Saúde

\section{Análise de dados}

Os dados que subsidiam a discussão apresentada neste texto são os registros do diário de campo do grupo e as reflexões das autoras que atuavam como facilitadoras das oficinas. Neste artigo será apresentada a discussão dos temas: (a) agente de saúde: que profissão é essa?; (b) o modelo neoliberal de atenção à saúde; (c) dificuldades de pensar o coletivo e de desconstruir as relações de gênero. Estes temas foram escolhidos porque permearam todas as oficinas e, quando não eram o foco das discussões, apareciam como pano de fundo para as outras questões apresentadas. O desenvolvimento das atividades será descrito a seguir com o intuito de explicitar sua implementação e a discussão dos temas evidenciados nas oficinas.

\section{Resultados e Discussão}

\section{Agente de saúde: que profissão é essa?}

A questão das dificuldades do trabalho esteve presente desde a primeira reunião com o grupo. Em todas as oficinas as agentes contavam histórias variadas sobre o trabalho. Às vezes falavam da sobrecarga de atividades, outras vezes falavam dos momentos em que se viam perdidas e sem saber como responder a algumas questões/demandas apresentadas pelos usuários. Falavam também sobre o modo como se ajudavam dentro de cada equipe evidenciando a existência de uma relação de proximidade. Essa temática atravessou transversalmente todas as oficinas e foi o tema central de três encontros.

Os temas emergiam de modos diferentes durante os encontros. Muitas vezes tinham origem nas dificuldades enfrentadas pelo grupo na Unidade de Saúde da Família (USF), outras vezes surgiam a partir de dificuldades individuais, como, por exemplo, quando algumas agentes utilizavam o espaço inicial do grupo para se queixarem das dificuldades encontradas em alguns casos que haviam atendido. A seguir, será relatado um breve resumo da primeira oficina em que o tema "Agente de saúde: que profissão é essa?" se tornou o foco da discussão.

\section{Oficina I}

Em princípio, as agentes discutiram a luta que haviam iniciado para a constituição de uma associação das agentes de saúde da zona leste e contaram que uma delas participava da associação como "delegada". Decidiu-se que nesse dia seria discutida essa questão. A partir de então, iniciou-se a identificação dos pontos prioritários para as agentes que deveriam ser incluídas na agenda da associação: (a) a importância de garantir o acesso de todas as agentes de saúde ao curso de capacitação básica, composto por três módulos, proposto pelo governo, mas que não estava disponível para todos; (b) exigir que os outros dois módulos do curso fossem oferecidos, já que apenas o primeiro módulo era disponibilizado à região e isso não motivava a participação das ACS, o curso foi lançado há quatro anos e até hoje os dois módulos complementares não foram disponibilizados para as agentes da zona leste; (c) a questão salarial é importante porque há agentes de saúde em outras Organizações Sociais que têm o salário maior.

Nesse dia, discutiu-se a importância da organização da categoria e explorou-se a experiência das participantes em grupos e associações. Ficou evidente que a participação e o exercício dos direitos e da cidadania eram muito difíceis para a maioria do grupo e que ainda existia a expectativa de 
que sempre "alguém" resolveria os seus problemas. O grupo decidiu que continuaria essa discussão na semana seguinte.

\section{Oficina II}

Iniciou-se a reunião com o curta-metragem "Gestão Participativa”. Esse documentário mostrava duas realidades onde a gestão participativa transformou a vida da população. Uma no município de Sobral-CE, onde a comunidade, organizada através de conselhos, conseguiu influenciar as políticas públicas e melhorar significativamente a qualidade de vida da população. A outra, com a experiência do orçamento participativo no município de Porto Alegre-RS, que destacava o modo como as pessoas participavam e as conquistas da população na eleição de prioridades e distribuição do orçamento de acordo com as necessidades locais. A discussão do filme foi muito interessante porque possibilitou ao grupo refletir sobre a comunidade onde vivem e as dificuldades que tem para se organizar. As agentes disseram que existem quatro Associações de Moradores no bairro e que as lideranças brigam entre si e não conseguem desenvolver um trabalho conjunto.

Nesse dia, discutiu-se sobre a importância da participação de todos para que um bairro ou comunidade possa crescer e melhorar. As agentes lembraram de uma experiência frustrada de mobilização da população local para limpar as margens do rio que passa nos fundos do bairro e de como é difícil contar com a participação de todos. Depois de analisar passo a passo a experiência de despoluição do rio, foi possível concluir que as pessoas participam quando acreditam na relevância da ação para as suas vidas e quando participam do processo de construção das ações.

\section{Oficina III}

As agentes iniciaram a oficina conversando sobre as exigências de que desempenhem papéis que não fazem parte de suas atribuições originais, tais como, a vigilância sanitária dos animais de rua, a fiscalização de caixas d'água, entre outras. Porém, apesar de realizarem essas ações "extras", a cobrança da produtividade não diminui, visto que devem visitar todas as famílias de sua área e conseguir cumprir todas as prioridades pré-estabelecidas. Essa exigência faz com que muitas vezes ultrapassem a jornada de trabalho de 40 horas semanais. Foi proposto e realizado um jogo que buscava trabalhar a confiança entre elas e elegeu-se o tema do dia, a saber, as múltiplas demandas para o agente de saúde. Havia duas posições diferentes e conflituosas dentro do grupo em relação às "atividades extras": algumas entendiam que tudo que diz respeito à saúde da população local é tarefa das agentes, outras entendiam que recolher os cachorros soltos pela rua, por exemplo, é tarefa do Serviço de Zoonoses. Outra questão que esteve muito presente foi a relação com os usuários, que muitas vezes as percebem como parceiras e aliadas nas questões de saúde e gostam de saber que são vizinhos, ao passo que, certas vezes, são culpadas por todas as lacunas do serviço de saúde, boicotando o seu trabalho.
Inicialmente, a discussão circulou em torno das reais possibilidades de ações intersetoriais e a relação do PSF com outros serviços, como zoonoses, vigilância sanitária e meio ambiente. Essa oficina possibilitou a discussão não somente sobre as múltiplas demandas existentes para as agentes de saúde, mas também sobre os diferentes modos pelos quais cada uma entende a profissão e vivência na prática essa experiência. Ao final da oficina, elas puderam expressar os motivos que as levaram a escolher e a permanecer nesse trabalho. Todas as participantes do grupo disseram estar nesse trabalho há mais de um ano.

Essas discussões reportaram, mais uma vez, ao estudo de Bornstein e Stotz (2008) quando comentam sobre a diversidade de papéis do ACS e o que se entende como sendo sua atribuição. As autoras chamam a atenção para as distorções do papel desse profissional e para os riscos da sobrecarga de trabalho a que pode estar submetido. Ressalta-se, ainda, a existência de diferentes concepções ético-políticas sobre a interface da saúde, das organizações comunitárias e dos sistemas/serviços governamentais.

As três oficinas evidenciaram o quanto as questões relativas à profissão são geradoras de angústias para as agentes e como elas estão se esforçando para construir uma identidade profissional e estabelecer limites para sua atuação como agentes de saúde. Foi interessante observar que, ao longo das oficinas, as relações foram se transformando e, gradativamente, dentro do grupo, elas passaram a valorizar mais a fala das colegas ao mesmo tempo em que se criou a possibilidade de expressar opiniões contrárias e explicitar conflitos.

Vale lembrar que, como afirmam Tirado e Gálvez (2007, p.5): "Por mais de duas décadas nas ciências sociais em geral e, mais especificamente, na Psicologia Social, tem ocorrido uma re-conceituação do fenômeno do conflito. A natureza negativa tem sido substituída por uma definição positiva". Isso quer dizer que há o reconhecimento da positividade dos conflitos entendidos como uma oportunidade de transformar a realidade e de encontrar novas formas de convivência. Nas oficinas os conflitos possibilitavam ampliar a compreensão da realidade. Nem sempre se chegava a consensos, porém as participantes aprenderam a reconhecer e a respeitar suas diferentes posições.

É interessante observar que nas oficinas apareceram várias queixas em relação ao sistema de saúde. Para as agentes de saúde desse grupo o sistema deixa muito a desejar em vários aspectos como no estabelecimento claro das funções, na inexistência de um plano de carreira e no reconhecimento e valorização das agentes de saúde. Por diversas vezes no decorrer das oficinas elas se referiram à necessidade de cursos de formação específica para agentes de saúde. No entanto, a implementação das políticas públicas de saúde dirigidas a esta categoria profissional tem sido muito lenta o que pode ser observado no fato de que, apesar da centralidade da figura do agente de saúde, somente em 10 de julho de 2002 a lei 10.507 instituiu a profissão de ACS (Morosini, D’Andrea Corbo, \& Guimarães, 2007). 


\section{O modelo neoliberal de atenção à saúde e as dificuldades de pensar o coletivo e as relações de gênero}

Desde as primeiras conversas com as lideranças locais e as sugestões dos possíveis temas a serem abordados num trabalho com as agentes de saúde, identificou-se que, dentre as atividades até então desenvolvidas com este grupo, não havia nenhum tipo de discussão sobre as relações de gênero e suas implicações nas relações sociais do cotidiano das pessoas.

No primeiro encontro com as agentes elas expressaram suas dificuldades em lidar, enquanto profissionais, com questões como violência doméstica e conflitos relativos aos papéis sociais de homens e mulheres. Decidiu-se que a discussão sobre gênero perpassaria transversalmente todas as outras e que seriam realizadas oficinas específicas com foco nas relações de gênero. Identificou-se, ainda, que apesar dos textos e diretrizes do Programa de Saúde da Família expressarem claramente a orientação para a promoção de saúde, na prática, era muito difícil para a ACS romper com o modelo tradicional de ações nesse setor, que foi denominado modelo neoliberal porque trata somente os indivíduos, responsabilizando-os por suas condições de vida e saúde.

Do ponto de vista da atenção em saúde, essa parece estar fundada em uma perspectiva biológico/tecnicista, onde os profissionais de saúde são vistos como "curadores de doenças" e que o binômio saúde-doença ainda é o foco privilegiado da atenção. É interessante observar que essa concepção permeia a sociedade brasileira e que, de modo geral, a população espera receber atenção à saúde focada no tratamento das doenças. Com isto, a transformação preconizada pelo PSF e pelas diretrizes do Sistema Único de Saúde (SUS) ocorre de forma lenta e gradual, ao passo que as agentes de saúde têm se esforçado muito para desconstruir esse modelo.

A seguir apresenta-se o resumo de duas oficinas onde os temas centrais foram as relações de gênero e a atenção integral à saúde.

\section{Oficina IV}

As agentes chegaram comentando sobre o fim de semana e uma delas, logo no início, falou sobre a solicitação da chefia para que elas fizessem grupos com adolescentes. Todas se mobilizaram com a discussão e algumas expressaram claramente sua recusa em fazer grupos. Elas diziam que é muito difícil desenvolver esse tipo de atividade e que as chefias exigem muitas coisas. Realizou-se uma atividade em que foi desenhado um adolescente do sexo masculino e uma adolescente do sexo feminino. Cada agente foi dizendo e desenhando o vestuário e as características físicas, psíquicas e sociais de cada um. A discussão foi muito interessante e elas expressaram as dificuldades que sentem em desconstruir as determinações de gênero historicamente atribuídas às mulheres e aos homens em nossa sociedade. No encerramento uma agente disse: "aqui falamos de coisas que eu nunca havia nem pensado".
Nessa oficina ficou bastante evidente que essas mulheres não tinham outras oportunidades de dialogar e refletir criticamente sobre as relações de gênero. Nesse sentido, Giffin (2002) apresenta uma interessante discussão sobre o modo como o discurso de gênero foi incorporado ao texto das políticas públicas, mas não tem sido operacionalizado nas práticas cotidianas, sendo usado muito mais para invisibilizar as desigualdades sociais.

Discutiu-se também as relações de trabalho e o fato de que, apesar dos grupos de promoção de saúde fazerem parte das diretrizes do PSF e a coordenação da USF solicitar que sejam realizados, estes somente são considerados nos relatórios de produtividade quando contam com dez ou mais participantes. Isso significa que, muitas vezes, os grupos com cinco ou seis participantes não podem ser incluídos nos relatórios, o que determina que o tempo gasto com os grupos não seja remunerado. Essa situação configura-se como um dos paradoxos do PSF, no qual se espera que sejam realizadas ações de promoção da saúde, porém, a organização do trabalho é focada no número de indivíduos e de famílias atendidas. Tal constatação conduz necessariamente à reflexão sobre o quanto o modelo neoliberal de atenção à saúde ainda é dominante.

Embora essa constatação possa representar uma situação pontual e, ainda que se enfatize a promoção de ações coletivas, o sistema de informação proposto para documentar as atividades (Sistema de Informação da Atenção Básica-SIAB) não oferece a possibilidade do detalhamento destas ações, o que pode inviabilizar o seu registro e demais encaminhamentos (Borsntein \& Stotz, 2008).

Outro aspecto levantado durante os encontros com as agentes foi a dificuldade na abordagem dos adolescentes no que se refere aos aspectos culturais, as expectativas que alimentam quanto aos seus projetos de vida, a gravidez na adolescência planejada ou não, a opção pelo uso de métodos contraceptivos e a necessidade de sigilo sobre as conversas que têm com os jovens do sexo masculino e feminino; as diversas práticas sexuais e as dúvidas trazidas pelos adolescentes. Ao final dessa oficina combinou-se que a temática continuaria sendo discutida no próximo encontro, descrito abaixo.

\section{Oficina $V$}

Iniciou-se assistindo ao filme "Meninas" de Sandra Wernec. Trata-se de um documentário que relata a história real de quatro adolescentes da periferia do Rio de Janeiro-RJ que ficam grávidas e decidem ter os bebês. Ao longo do filme é mostrado o cotidiano de cada uma das meninas, o trabalho doméstico, as relações com a mãe, irmãos, pai (quando ele está presente) e com o pai da criança. Aparece também a relação com o sistema de saúde e as expectativas de cada uma em relação ao futuro. O filme é realizado durante os nove meses de gravidez e nos primeiros três meses de vida das crianças. Ao final do filme, a discussão focalizou o modo de vida das adolescentes e as agentes buscaram entender a 
trajetória de cada uma e suas escolhas. Elas disseram que as histórias das meninas e meninos que aparecem no filme não são muito diferentes daquelas do bairro em que vivem e trabalham.

As agentes se emocionaram com o filme e a discussão foi permeada por risos e lágrimas. Elas explicitaram as suas dificuldades pessoais para lidar com as diferenças geracionais e culturais. Apesar de o filme transcorrer no Rio de Janeiro, elas identificaram muitas similaridades com a situação dos adolescentes em São Paulo e fizeram uma revisão da própria história e das vivências da adolescência.

\section{Considerações finais}

As oficinas configuraram-se como espaço de diálogo muito importante e possibilitaram a discussão sobre promoção de saúde e gênero, o papel profissional das agentes de saúde e o modelo neoliberal de atenção à saúde. Entre os problemas presentes nos discursos desse grupo ficou evidente a ausência de uma rede de serviços na região que possibilite às agentes ampliar a resolutividade de suas ações por meio de encaminhamentos para outros serviços. Portanto, faz-se necessário buscar desenvolver e articular essa rede para que o Programa de Saúde da Família possa alcançar os objetivos pretendidos.

Este trabalho permitiu, também, a reflexão sobre a importância de se considerar que os agentes "promotores" de saúde também são indivíduos que trazem consigo suas histórias e experiências que permanecem presentes no cotidiano de suas vidas permeando suas práticas profissionais. Atentar para essa interação pode facilitar a compreensão das relações serviço-comunidade-usuário-profissional e auxiliar na superação de preconceitos e no processo de transformação social.

Outra discussão muito presente foi sobre o modo como as relações de gênero permeiam o trabalho das agentes de saúde na comunidade e a necessidade de compreender as relações de poder envolvidas nos "lugares" socialmente construídos para homens e mulheres para que se possa efetivamente realizar ações de promoção de saúde. Nesse sentido, vale ressaltar a potencialidade da perspectiva construcionista social para orientar ações dirigidas à desnaturalização de questões tidas, muitas vezes, como historicamente naturais, como por exemplo, as diferenças de gênero. Tal perspectiva pode, ainda, embasar metodologias participativas e dialógicas como estratégia para a formação continuada em saúde.

Salienta-se também que a possibilidade de discutir questões centrais do dia-a-dia, bem como as situações difíceis para o grupo, possibilitou a todos os envolvidos a construção de novos saberes e aprendizagens, tanto de novos conteúdos como de novas formas de se relacionar com o outro. Partir da experiência e dos saberes pré-existentes possibilitou ao grupo explorar suas dificuldades e incorporar outras possibilidades de pensar e agir. As metodologias participativas diferem, em sua forma e conteúdo, das metodologias de ensino em que os temas a serem discutidos são eleitos a priori por gestores ou por professores e quase sempre não oferecem a oportunidade para que os sujeitos envolvidos exercitem a autonomia no processo de aprendizagem.

\section{Referências}

Bornstein, V. J., \& Stotz, E. N. (2008). Concepções que integram a formação e o processo de trabalho dos agentes comunitários de saúde: Uma revisão da literatura [Versão eletrônica]. Ciência \& Saúde Coletiva, 13, 259268. Recuperado em 31 janeiro 2009, de http://www. scielo.br/scielo.php?script $=$ sci_arttext\&pid $=$ S1413$81232008000100029 \& \operatorname{lng}=$ pt\&nrm $=$ iso

Brigagão, J. I. M., \& Oliveira, F. M. (2005). Programa Paidéia de saúde da família: Uma reformulação nas práticas e na produção de saúde. Cadernos Gestão Pública e Cidadania, 10, 45-56.

Câmara Municipal de São Paulo. (2007). Zona Leste: Seminário discute desenvolvimento da região. Recuperado em 13 maio 2008, de http://www.camara. sp.gov.br/noticias_detalhe.asp?id=1012

Campos, W. S. G. (2005). Saúde paidéia. São Paulo: Hucitec.

Freire, P. (1996). Pedagogia da autonomia: Saberes necessários à prática educativa. São Paulo: Paz e Terra.

Giffin, K. (2002). Pobreza, desigualdade e equidade em saúde: Considerações a partir de uma perspectiva de gênero transversal [Versão eletrônica]. Cadernos de Saúde Pública, 18(Supl.), 103-112. Recuperado em 02 maio 2008, de http://www.scielo.br/pdf/csp/v18s0/13797. pdf

Iñiguez, L. (2004). Análisis del discurso: Manual para las ciencias sociales. Barcelona, Espanha: UOC.

Kluthcovsky, A. C. G. C., \& Takayanagui, A. M. M. (2006). O agente comunitário de saúde: Uma revisão da literatura [Versão eletrônica]. Revista Latino-Americana de Enfermagem, 14, 957-963. Recuperado em 31 janeiro 2009, de http://www. scielo.br/scielo.php?script $=$ sci_arttext\&pid=S0104$11692006000600019 \& \operatorname{lng}=$ en\&nrm=iso.

Morosini, M. V., D’Andrea Corbo, A., \& Guimarães, C. C. (2007). O agente comunitário de saúde no âmbito das políticas voltadas para a atenção básica: Concepções do trabalho e da formação profissional [Versão eletrônica]. Trabalho, Educação e Saúde, 5, 261-280. Recuperado em 26 abril 2008, de http://www.revista.epsjv.fiocruz.br// include/mostrarpdf.cfm?Num=170.

Oliveira, P. C., \& Carvalho P. (2007). A intencionalidade da consciência no processo educativo segundo Paulo Freire. Paidéia (Ribeirão Preto), 17, 219-230.

Spink, M. J. (2004). (Org.). Práticas discursivas e produção de sentidos no cotidiano: Aproximações teóricas e metodológicas. São Paulo: Cortez. 
Tirado, F., \& Gálvez, A. (2007). Positioning theory and discourse analysis: Some tools for social interaction analysis [Versão eletrônica]. Forum Qualitative Sozialforschung / Forum: Qualitative Social Research, 8(2), Art. 31. Recuperado em 24 abril 2008, de http:// www.qualitative-research.net/fqs-texte/2-07/07-2-31-e. $\mathrm{htm}$

Jacqueline Isaac Machado Brigagão é Professora Doutora do Curso de Obstetrícia da Escola de Artes, Ciências e Humanidades da Universidade de São Paulo.

Roselane Gonçalves é Professora Doutora do Curso de Obstetrícia da Escola de Artes, Ciências e Humanidades da Universidade de São Paulo.

Recebido: 07/06/2008

$1^{a}$ revisão: 02/02/2009

$2^{a}$ revisão: 03/03/2009

$3^{a}$ revisão: 26/03/2009

Aceite final: 05/04/2009 